\title{
The post-move satisfaction of internal migrants
}

\author{
Michael K. Sloan ${ }^{\dagger, *}$ and Philip S. Morrison* \\ †School of Geography, Environment and Earth Sciences, Victoria University of Wellington, Wellington, 6012, New \\ Zealand and School of Geography, Environment and Earth Sciences, Victoria University of Wellington, Wellington, \\ 6012, New Zealand \\ ${ }^{*}$ Corresponding author. Email: mks.nzl@gmail.com
}

\begin{abstract}
Research on internal migration within and between countries has been dominated by the search for patterns and causes, and while more attention is being paid to the consequences of such movement, only recently has attention shifted to the migrants' own appraisal of their move. Most models of migration are predicated on the reasonable assumption that migrants will not move voluntarily unless they believe they are going to be better off. It is a big step, however, to then assume that all or even most migrants end up better off. Outcome measures such as wages and income typically show substantial variation around a positive average improvement and a minority typically result in losses. The relatively new body of literature on post-move satisfaction draws attention to the fact that returns to moving can be measured in subjective as well as objective terms and these two reveal considerable variation as to the success of changing where one lives. In this paper we use a unique survey of individuals moving within New Zealand to model the variation in subjective returns to moves both within and between local labour markets (using the attributes of movers and the moves themselves as arguments).
\end{abstract}

Keywords: internal migration, local labour markets, outcome, residential mobility

\section{Introduction}

It is assumed that people view the migration decision as one of utility maximization, i.e., they migrate in order to become better off in some subjective sense. (Ziegler and Britton 1981: 304)

There is a longstanding tendency in the migration literature to focus on the determinants of moving rather than its consequences (De Jong, Chamratrithirong and Tran 2002). Certainly, from a macroeconomic perspective, 'little has been done to determine the influence of migration as an equilibrating mechanism in a changing economy' (Sjaastad 1962). While a great 
deal of progress has since been made in understanding how migration contributes to national development, the focus at the micro or individual level has remained largely on the objective or externally identifiable outcomes involving both employment and wages (De Jong, Chamratrithirong and Tran 2002). By comparison, and despite the rise of micro-behavioural approaches, non-pecuniary outcomes in general and subjectively experienced outcomes in particular have been given far less attention (De Jong, Chamratrithirong and Tran 2002; Lu 2002; Lundholm and Malmberg 2006; Nowok et al. 2011).

Studies of repeat and return migration are two explicit indications that not all moves improve people's livelihood (Kau and Sirmans 1976; DaVanzo 1981; Grant and Vanderkamp 1986), for moves that do not live up to the mover's expectations greatly increase the propensity of a further move (Yezer and Thurston 1976; Allen 1979). However, most moves that fall short of expectations probably do not result in relocation and without actually studying the post-move experience itself it is difficult to gauge just how successful such outcomes are. While it may be convenient for modelling purposes to assume that rational individuals will realise a positive outcome (Massey et al. 1993), in practice the net outcomes range widely from the very negative to the very positive in both objective and subjective terms (De Jong, Chamratrithirong and Tran 2002; Lu 2002; Barcus 2004; Lundholm and Malmberg 2006; Nowok et al. 2011).

Our contribution to the migration literature focuses on those subjectively experienced outcomes reported by the movers themselves, and how they vary by movers' demographic and socio-economic characteristics as well as the characteristics of the move itself. With respect to the latter, we partition the country into local labour markets in order to differentiate between the 'mobility' within such markets and the 'migration' between them.

The paper is organized as follows. Section 2 introduces the post-move satisfaction literature. Section 3 outlines our conceptual framework. Section 4 introduces the sample survey and model. Section 5 reports the post-move satisfaction experience of those moving within local labour markets and section 6 models migration between them. Our conclusions are presented in section 7 .

\section{Post-move satisfaction}

Post-move satisfaction is a recent body of literature which addresses changes in the subjective well-being of movers associated with their change of residence, both within and between countries. As observed in a recent review, 'most casual observers would think that happiness and migration are positively related', but 'the relationship between migration and happiness is relatively unexplored in the literature, and in particular the economics literature' (Simpson 2011). The few studies published to date are part of a more general tendency to complement objective measures of economic outcomes with broader assessments of such changes in subjective terms (De Jong, Chamratrithirong and Tran 2002; European Commission 1994; Nowok et al. 2011). The literature now regularly demonstrates the importance of non-economic dimensions as motivations for internal migration, while at the same time not discarding the importance of economic factors as a constraint (Morrison and Clark 2011). 
So far there is little consensus about the difference mobility and migration actually makes to people's own level of subjective well-being. In one of the earlier studies, higher satisfaction following a move was found to be experienced by only a minority of Thai rural-urban migrants (De Jong, Chamratrithirong and Tran 2002). In a subsequent study of urban to rural migration in the USA, merely ' $52 \%$ of migrants rated their new location better' (Barcus 2004: 655). In yet another study, only about one half of US movers rated their new housing conditions better than their previous housing, while approximately $40 \%$ rated their neighbourhood as better ( $\mathrm{Lu}$ 2002). Results from the five Nordic countries showed a more positive evaluation of migration with $83 \%$ feeling better off following their move, but the remainder reported either no change in their satisfaction or a decrease (Lundholm and Malmberg 2006). There are many confounding issues in making such comparisons and one of these concerns the reference group.

Two studies of internal migrants in China have recently drawn attention to the importance of the reference group in determining whether the move is deemed a success in terms of subjective well-being (Knight and Gunatilaka 2010). Subsequent studies have shown just how crucial the reference group is to any judgement about the outcomes of moves be they internal to a country (Akay and Bargain 2012) or international migration (Bartram 2011, 2013). So too is identifying the level of well-being before the move (Polgreen and Simpson 2011).

The small post-move satisfaction literature lacks a consensus on which factors lead to variations in the post-move satisfaction outcomes of movers and migrants. The lack of consensus is in part due to the range of measures upon which post-move satisfaction is measured. Socio-economic factors have been found to only have a limited influence on the reported change in the post-move satisfaction of migrants (Lundholm and Malmberg 2006). Despite gender differences observed in economic terms following a move (Mincer 1978; Cooke 2008), men and women have been found to experience similar overall postmove satisfaction outcomes, while cohabiting with a partner has been associated with higher satisfaction than not living with a partner (Lu 2002; Lundholm and Malmberg 2006; Nowok et al. 2011). Higher education has been associated with lower satisfaction outcomes, potentially due to the more educated sacrificing short term satisfaction for more positive career outcomes (Lundholm and Malmberg 2006). The income level of movers has an insignificant effect on their post-move satisfaction (Barcus 2004; Lu 2002). Moving to more rural areas has been found to result in a lower quality of life despite the hypothesized less stressful lifestyle of rural life (Chhetri et al. 2009), while others have identified an insignificant association between population density and post-move satisfaction outcomes (Lu 2002, Lundholm and Malmberg 2006).

Although some forced movers may be able to take advantage of the move in order to seek a destination that better suits their needs (Kleinhans 2003), involuntary moves are strongly associated with lower post-move satisfaction than moves undertaken voluntarily (Lundholm and Malmberg 2006). The negative association of involuntary moves may be due to less favourable life circumstances in general, or a hastier decision-making process (Rossi 1955). The importance of a well-considered move is reinforced by the higher post-move satisfaction of individuals who cite multiple reasons for moving, even if the primary reason given for moving has a weak association with overall satisfaction (Lundholm and Malmberg 2006). 
In summary, a growing literature on the impacts of migration on movers suggests that there are different ways of capturing subjective evaluations, that such evaluations are highly variable across the population who change address over a given period, that they depend on the reference group comparisons and, despite positive expectations, a proportion of movers are unable to report positively on the outcomes of their move. While the existing literature identifies some of the factors that may be associated with variations in post-move satisfaction, there remains a lack of conformity.

\section{Conceptual framework}

The early literature on post-move satisfaction address three issues: what is post-move satisfaction, the nature of the reference group and the way satisfaction tracks before and after the move. The use of life satisfaction measures has lead Haybron among others to draw attention to the fact that responses to life satisfaction questions are largely measures of relative position rather than a guide to any absolute measure of personal well-being and that life satisfaction is only weakly related to well-being as an absolute condition (Haybron 2011). Changes in life satisfaction or happiness tell us little about how well these individuals are doing in an objective sense and much more about changes in how migrants and comparison groups view changes in their relative circumstances resulting from the move.

One of the main points of reference that migrants use is their self in the past; the other is their progress relative to specific reference groups, non-movers or fellow migrants among others. Our own approach to conceptualising post-move satisfaction recognizes each of these points. Figure 1 expresses the relationship between expectations and their realization. Assuming an appropriate metric, our framework recognizes that migrants vary in their expectations (E) and that they will also differ in the degree to which these expectations are realized through the move $(\mathrm{R})$. If the movers' expectations are realized, i.e. $\mathrm{R}=\mathrm{E}$, it is reasonable to expect this will be a source of (positive) satisfaction ( $S$ ) with the move and the perceived outcome of the move will be positive. If realizations are lower than expected $\mathrm{R}_{1}<$ $E_{1}$, then the migrant is likely to be dissatisfied and sit below the diagonal, at say $S_{1}$. When events exceed expectations, $R_{2}>E_{2}$, $S$ will appear above the diagonal, as in $S_{2}$, for example, thereby yielding an even higher level of satisfaction; $S_{2}>S>S_{1}$.

According to the argument which underpins Figure 1, the further to the left $S$ is from the diagonal the greater the degree of satisfaction with the outcome of the move and the further to the right the greater the dissatisfaction. Quite clearly, as Haybron points out, being at $S_{2}$ rather than $S_{1}$ does not mean that one's well-being is any better in any absolute sense, only that the mover is more satisfied than at $\mathrm{S1}$. Satisfaction in the sense we use it in this paper is therefore the level of well-being as a result of the move.

\section{Data and method}

In the empirical account to follow we draw on the purpose built 2007 Survey of Dynamics and Motivations for Migration in New Zealand (DMM) conducted by Statistics New Zealand. The DMM survey was administered as a supplement to the Household Labour 


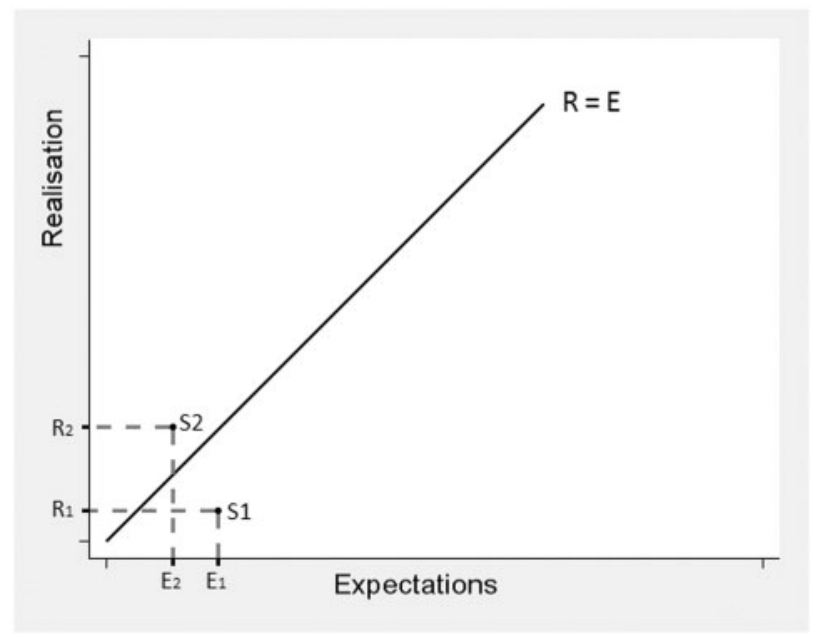

Figure 1. Post-move satisfaction as the difference between expectation and realisation.

Force Survey (HLFS) in the March quarter of 2007. As such the DMM survey was able to access a pre-existing nationally representative sample of about 15,000 households, equating to approximately 30,000 individuals over the age of 15 (Statistics New Zealand 2009). Respondents to the HLFS survey were asked to participate in the DMM survey over the period 7 January to 7 April 2007, provided they were living in occupied private dwellings. The response rate to the DMM supplement was 77.9 per cent, slightly below the target response rate, resulting in a total sample size of 23,465 individual responses from 13,841 households.

Of these 23,465 sampled individuals, 24 per cent had moved within New Zealand over the two years prior to being interviewed. Those who had moved more than once in the twoyear period were only asked about the characteristics of their most recent move. Of those whose most recent move was within New Zealand, 4,796 respondents provided enough information to be included in the analysis below.

In accordance with our conceptual framework above the survey asks those who changed residence within the country between 2005 and 2007: 'Overall, how satisfied or dissatisfied are you with the way things have worked out since you moved?' There were five response options: very satisfied, satisfied, equally satisfied and dissatisfied, dissatisfied or very dissatisfied. The primary virtue of the question, as Statistics New Zealand has asked it, is that it secures a measure of satisfaction attributable to the move or migration.

In order to differentiate residential mobility from migration we distinguish between movements within and between local labour markets (LLM). Conceptually the former involves a change in the dwelling within the persons' local labour market, whereas internal migration is defined as a simultaneous change of both the dwelling and the workplace (Zax 1994). Unfortunately, the DMM survey does not specifically ask respondents to identify 
their workplace, therefore we have operationalized the concept of the local labour market by subdividing New Zealand into a set of mutually exclusive local labour markets based on 2006 census data - a date the DMM survey was deliberately designed to straddle. This procedure was based on an algorithm that partitioned space according to commuting data (Papps and Newell 2002). The relevant maps may be found in Morrison and Clark (2011). While not completely separating mobility from migration, our empirical delimitation is the best approximation we could achieve with the data at hand.

Our interest lay in understanding the variation in the level of post-move satisfaction expressed by movers and migrants. We therefore specified the following regression model:

$$
y_{i}=\alpha+\beta X_{i}+\varepsilon_{i}
$$

where $y_{i}$ is the ordinal measure of 'satisfaction with the way things worked out since you moved' as reported by the $i$ th individual mover or internal migrant, $X_{i}$ is a vector of arguments; $\alpha$ and $\beta$ are the parameters to be estimated and $\varepsilon_{i}$ is the error term. ${ }^{1}$

When it comes to the dependent variable $y$, we find a majority of movers $(87 \%)$ were either satisfied or very satisfied with the outcomes of their move over the two year period. The distribution is shown in Figure 2. A minority expressed dissatisfaction with the outcome of their move and a minority were very dissatisfied. There was little difference between those moving within and between local labour markets and the slightly more negative skew experienced by those moving within local labour markets has also been reported elsewhere (Lundholm and Malmberg 2006).

The most common method of estimating model 1 is the ordinal logit model. While the ordinal model is advocated by some (McKelvey and Zavoina 1975; Lu 1999), others have recognized how applying OLS yields essentially comparable results (Ferrer-i-Carbonell and Frijters 2004; Clark et al. 2008). The presumption one is modelling a cardinal measure greatly eases the interpretation of estimated coefficients (as opposed to the more convoluted interpretation involving cut-points output from ordinal probit or logit). The fact that for practical purposes the two methods yield virtually identical results has been the main reason why OLS is preferred in many contemporary social science applications (Nowok et al. 2011; Ryan 2012) and we adopt this current practice for the same reasons. ${ }^{2}$

Table 1 summarizes the characteristics of the New Zealand respondents. Those changing their address over the two year period 2005-2007 were on average young (37 years), and had typically moved several times in the previous 10 years. Women comprised a slightly higher proportion of the sample than men (57\%). Over half of movers (53\%) undertook their move with a partner and approximately $12 \%$ had changed cohabitation status relative to before the move. Four of every five had moved voluntarily.

At the same time, there were some notable differences in the characteristics of movers and migrants. Those migrating to a different local labour market were more likely to have experienced a change in income ( $22 \%$ more likely), particularly a decrease in income ( $17 \%$ more likely). Internal migrants changing markets in this way were also more likely to be unemployed or out of the labour force and tended to earn less than average. Other socioeconomic differences may be read off Table 1.

In addition to the socio-economic characteristics of movers, the $\mathrm{X}$ vector in equation (1) above also includes the difference in the level of deprivation of neighbourhoods before and after the move. These have been based on the New Zealand Deprivation Index 2006 

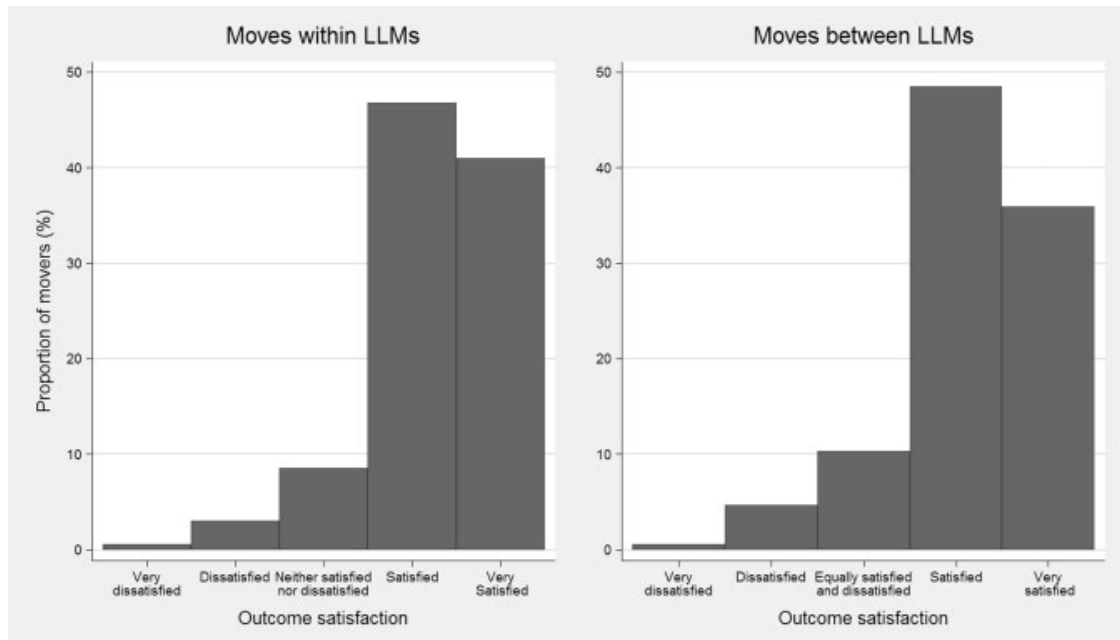

Figure 2. Distribution of post-move satisfaction responses by movers and migrants, New Zealand, 2005-2007. Source: Statistics New Zealand, 2007.

(White et al. 2008) which is a relative measure of socio-economic deprivation across small areas. Variables used in constructing this index include individual and household income, home ownership, family support, employment, qualifications and transport accessibility.

\section{Moving within the local labour market}

Our estimates of the parameters in equation (1) shows that the satisfaction movers report with the outcomes of their move are associated with both their own characteristics and that of the move itself. Working down Table 2 we learn first that the average level of satisfaction with the move increases with the length of time spent at a new address. In this crosssectional survey satisfaction peaks 6 to 9 months after the move at 0.16 points higher than the level of satisfaction reported by the most recent movers, the base. ${ }^{3}$ Clearly there is a process of adjustment to the new place and in this respect the cross sectional evidence is consistent with the adjustment sequence documented from longitudinal data (Nowok et al. 2013).

In respect to the next variable, age, we expected that the past experience characteristic of older movers would have improved their decision-making process and that realization would align more closely with expectations. However, the level of post-move satisfaction increased only slightly with the respondent's age and the association itself was weak. Experience does count, however, for we found that those who had previously undertaken at least one other move in the 10 years prior to their latest move (three, in Table 2) were more satisfied with the outcomes of their current move. By contrast, those moving more 
Table 1. Description of the independent variables used in the analysis of post-move satisfaction

\begin{tabular}{|c|c|c|c|c|c|}
\hline \multirow[t]{2}{*}{ Variable } & \multirow[t]{2}{*}{ Categories } & \multicolumn{4}{|c|}{ Frequency $(\%)$ or mean } \\
\hline & & Overall & Intra-LLM & Inter-LLM & Difference \\
\hline Distance (mean) & $\mathrm{km}$ & 61.4 & 5.3 & 265.4 & 260.1 \\
\hline \multirow[t]{2}{*}{ LLM change } & No change* & 78.4 & - & - & - \\
\hline & Change & 21.6 & - & - & - \\
\hline \multirow{5}{*}{$\begin{array}{l}\text { Time since } \\
\text { move }\end{array}$} & $0-3$ months & 21.2 & 20.3 & 24.7 & 4.4 \\
\hline & 3-6 months & 15.3 & 15.3 & 15.4 & 0.1 \\
\hline & 6-9 months & 15.7 & 16.3 & 13.7 & -2.6 \\
\hline & 9-12 months & 13.2 & 13.3 & 12.7 & -0.6 \\
\hline & $1-2$ years* & 34.4 & 34.7 & 33.6 & -1.1 \\
\hline Age (mean) & Years & 36.9 & 36.7 & 37.5 & 0.8 \\
\hline \multirow{4}{*}{$\begin{array}{l}\text { Dwellings in } \\
\text { previous } 10 \\
\text { years }\end{array}$} & Two & 20.2 & 19.4 & 23.4 & 4.0 \\
\hline & Three & 22.3 & 22.3 & 22.4 & 0.1 \\
\hline & Four & 16.5 & 16.8 & 15.3 & -1.5 \\
\hline & Five or more* & 41.0 & 41.6 & 38.9 & -2.7 \\
\hline \multirow{6}{*}{$\begin{array}{l}\text { Ethnicity(movers } \\
\text { were able } \\
\text { to identify } \\
\text { with multiple } \\
\text { ethnicities) }\end{array}$} & European* & 73.2 & 72.3 & 76.9 & 4.6 \\
\hline & Māori & 15.6 & 15.4 & 16.0 & 0.6 \\
\hline & Chinese & 3.3 & 3.4 & 2.8 & -0.6 \\
\hline & Indian & 3.4 & 3.5 & 2.6 & -0.9 \\
\hline & Pacific & 5.6 & 6.0 & 3.8 & -2.2 \\
\hline & $\begin{array}{l}\text { Not otherwise } \\
\text { Identified }\end{array}$ & 4.6 & 4.9 & 3.4 & -1.5 \\
\hline \multirow[t]{2}{*}{ Sex } & Male & 43.5 & 42.9 & 45.5 & 2.6 \\
\hline & Female* & 56.5 & 57.1 & 54.5 & -2.6 \\
\hline \multirow[t]{5}{*}{$\begin{array}{l}\text { Cohabitation } \\
\text { status }\end{array}$} & $\begin{array}{l}\text { Existing } \\
\text { couple* }\end{array}$ & 53.0 & 53.7 & 50.0 & -3.7 \\
\hline & New couple & 5.3 & 5.3 & 5.3 & 0.0 \\
\hline & $\begin{array}{c}\text { Different } \\
\text { couple }\end{array}$ & 0.6 & 0.6 & 0.7 & 0.1 \\
\hline & Still single & 35.6 & 34.9 & 38.1 & 3.2 \\
\hline & Newly single & 5.5 & 5.4 & 5.9 & 0.5 \\
\hline \multirow[t]{4}{*}{ Education } & None & 22.7 & 22.7 & 22.7 & 0.0 \\
\hline & Secondary & 24 & 23.9 & 24.5 & 0.6 \\
\hline & Post-School* & 38.4 & 38.1 & 39.4 & 1.3 \\
\hline & $\begin{array}{l}\text { Bachelor or } \\
\text { higher }\end{array}$ & 15.0 & 15.3 & 13.3 & -2.0 \\
\hline
\end{tabular}


Table 1. Continued

\begin{tabular}{|c|c|c|c|c|c|}
\hline \multirow[t]{2}{*}{ Variable } & \multirow[t]{2}{*}{ Categories } & \multicolumn{4}{|c|}{ Frequency $(\%)$ or mean } \\
\hline & & Overall & Intra-LLM & Inter-LLM & Difference \\
\hline \multirow[t]{6}{*}{ Income } & Unknown & 5.4 & 5.5 & 5.6 & 0.1 \\
\hline & Negative or $\$ 0$ & 5.9 & 5.7 & 6.4 & 0.7 \\
\hline & $\$ 1-\$ 20,000^{*}$ & 30.7 & 29.2 & 36.4 & 7.2 \\
\hline & $\begin{array}{l}\$ 20,001- \\
\$ 40,000\end{array}$ & 30.4 & 30.9 & 28.5 & -2.4 \\
\hline & $\$ 40,001-70,000$ & 21.5 & 22.3 & 18.0 & -4.3 \\
\hline & $\$ 70,000+$ & 6.2 & 6.4 & 5.1 & -1.3 \\
\hline \multirow{3}{*}{$\begin{array}{l}\text { Income change } \\
\text { (compared } \\
\text { with one year } \\
\text { earlier) }\end{array}$} & Increased & 25.9 & 24.8 & 30.0 & 5.2 \\
\hline & $\begin{array}{l}\text { Stayed the } \\
\text { same* }\end{array}$ & 60.8 & 65.5 & 43.6 & -22.0 \\
\hline & Decreased & 13.2 & 9.6 & 26.5 & 16.9 \\
\hline \multirow[t]{6}{*}{$\begin{array}{l}\text { Labour force } \\
\text { status }\end{array}$} & $\begin{array}{l}\text { Not in labour } \\
\text { force* }\end{array}$ & 25.7 & 24.2 & 30.8 & 6.6 \\
\hline & Unemployed & 6.1 & 5.4 & 8.6 & 3.2 \\
\hline & $\begin{array}{l}\text { Managers and } \\
\text { professionals }\end{array}$ & 26.3 & 27.4 & 22.1 & -5.3 \\
\hline & $\begin{array}{c}\text { Trades and } \\
\text { services }\end{array}$ & 22.5 & 24.3 & 16.6 & -7.7 \\
\hline & $\begin{array}{c}\text { Primary and } \\
\text { secondary }\end{array}$ & 13.1 & 13.3 & 11.9 & -1.4 \\
\hline & Unknown & 6.4 & 5.4 & 10.1 & 4.7 \\
\hline \multirow{3}{*}{$\begin{array}{l}\text { Urban hierarchy } \\
\text { change }\end{array}$} & Upward & 13 & 5.5 & 40.1 & 34.6 \\
\hline & Lateral* & 75.2 & 89.6 & 22.6 & -67.0 \\
\hline & Downward & 11.8 & 4.9 & 37.3 & 32.4 \\
\hline $\begin{array}{l}\text { Neighbourhood } \\
\text { deprivation } \\
\text { change (mean) }\end{array}$ & $\begin{array}{l}\text { Change in } \\
\text { deciles }\end{array}$ & 0 & 0 & 0 & 0 \\
\hline \multirow[t]{2}{*}{ Forced moves } & Voluntary* & 81.0 & 79.6 & 85.6 & 6.0 \\
\hline & Forced & 19.0 & 20.4 & 14.4 & -6.0 \\
\hline \multirow{7}{*}{$\begin{array}{l}\text { Reasons for } \\
\text { moving from } \\
\text { previous } \\
\text { address }\end{array}$} & Social & 21.4 & 20.7 & 23.9 & 3.2 \\
\hline & Educational & 3.9 & 2.6 & 8.4 & 5.8 \\
\hline & Employment & 10.4 & 4.9 & 30.5 & 25.6 \\
\hline & Economic* & 32.4 & 38.0 & 12.0 & -26.0 \\
\hline & Housing & 18.0 & 21.3 & 6.1 & -15.2 \\
\hline & Environment & 9.1 & 8.0 & 13.1 & 5.1 \\
\hline & Other & 4.8 & 4.5 & 5.9 & 1.4 \\
\hline \multirow[t]{2}{*}{ Multiple motives } & One* & 67.9 & 69.5 & 62.3 & -7.2 \\
\hline & Multiple & 32.1 & 30.5 & 37.7 & 7.2 \\
\hline
\end{tabular}

* Denotes reference category. Source: Statistics New Zealand, 2007 
Table 2. Linear regression, moves within labour markets, New Zealand, 2007

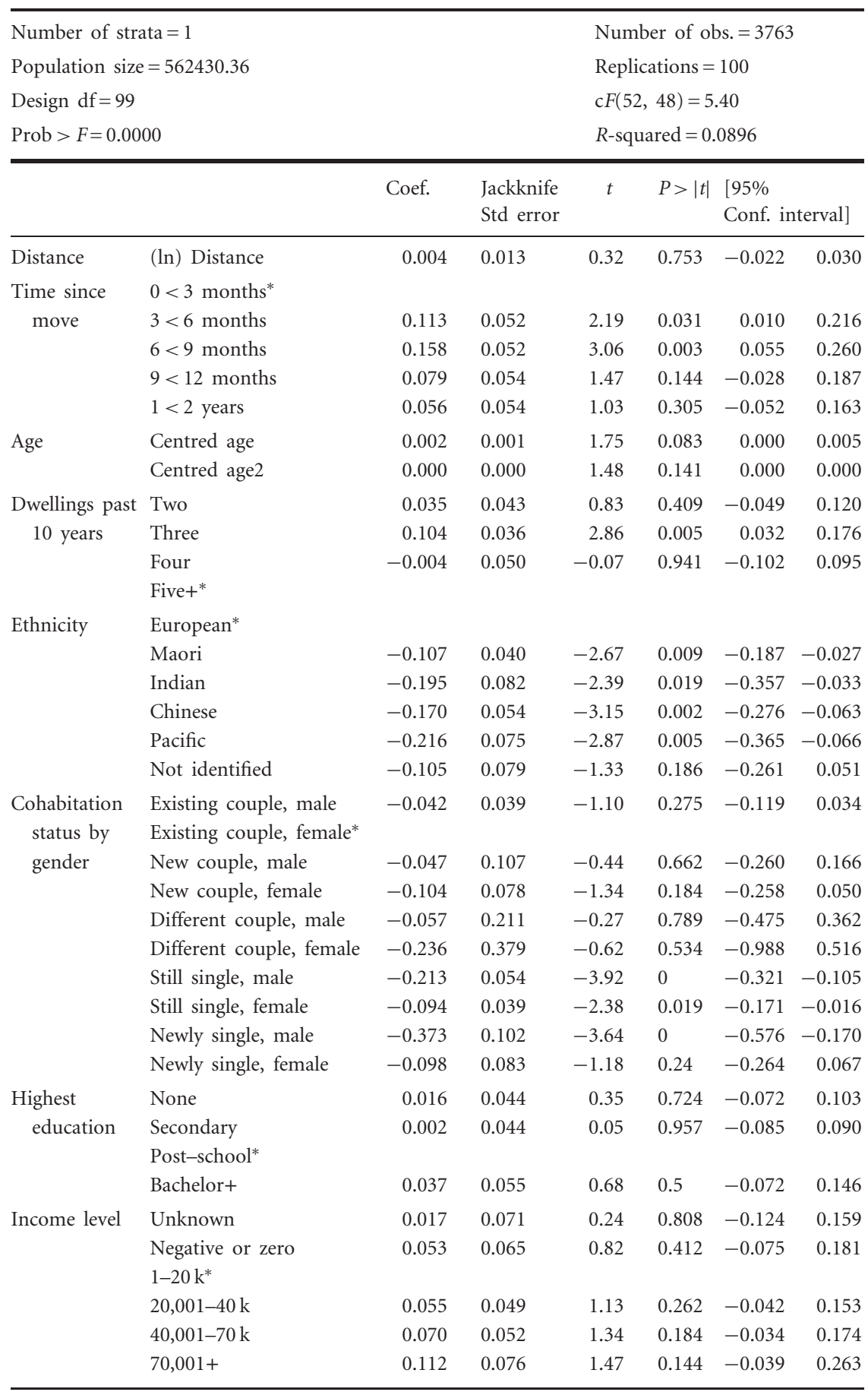


Table 2. Continued

\begin{tabular}{|c|c|c|c|c|c|c|c|}
\hline \multirow{3}{*}{$\begin{array}{c}\text { Change in } \\
\text { income }\end{array}$} & \multirow[b]{2}{*}{ No change* } & \multirow[t]{2}{*}{ Coef. } & \multirow[t]{2}{*}{$\begin{array}{l}\text { Jackknife } \\
\text { Std error }\end{array}$} & \multirow[t]{2}{*}{$t$} & \multirow[t]{2}{*}{$P>|t|$} & \multicolumn{2}{|c|}{$\begin{array}{l}{[95 \%} \\
\text { Conf. interval] }\end{array}$} \\
\hline & & & & & & & \\
\hline & + (result of move) & 0.124 & 0.059 & 2.12 & 0.037 & 0.008 & 0.241 \\
\hline & + (unrelated to move) & 0.101 & 0.033 & 3.07 & 0.003 & 0.036 & 0.166 \\
\hline & - (result of move) & -0.222 & 0.105 & -2.13 & 0.036 & -0.430 & -0.015 \\
\hline & - (unrelated to move) & -0.056 & 0.061 & -0.92 & 0.358 & -0.177 & 0.064 \\
\hline \multirow[t]{6}{*}{ Occupation } & Not in labour force* & & & & & & \\
\hline & Unemployed & -0.084 & 0.082 & -1.02 & 0.308 & -0.247 & 0.079 \\
\hline & Managers \& professionals & 0.127 & 0.060 & 2.13 & 0.035 & 0.009 & 0.246 \\
\hline & Trades \& services & 0.117 & 0.066 & 1.76 & 0.082 & -0.015 & 0.249 \\
\hline & Primary \& secondary & -0.044 & 0.074 & -0.60 & 0.548 & -0.190 & 0.102 \\
\hline & Unknown & 0.027 & 0.082 & 0.33 & 0.742 & -0.135 & 0.189 \\
\hline \multirow{4}{*}{$\begin{array}{l}\text { Urban hierar- } \\
\text { chy change }\end{array}$} & Up & 0.039 & 0.082 & 0.48 & 0.635 & -0.123 & 0.201 \\
\hline & Lateral* & & & & & & \\
\hline & Down & 0.019 & 0.078 & 0.24 & 0.81 & -0.136 & 0.174 \\
\hline & Deprivation change & -0.014 & 0.005 & -2.91 & 0.005 & -0.024 & -0.005 \\
\hline \multirow[t]{2}{*}{ Forced } & $\mathrm{No}^{*}$ & & & & & & \\
\hline & yes & -0.144 & 0.045 & -3.22 & 0.002 & -0.233 & -0.055 \\
\hline \multirow{7}{*}{$\begin{array}{l}\text { Main reason } \\
\text { for moving }\end{array}$} & Social & -0.043 & 0.039 & -1.10 & 0.272 & -0.119 & 0.034 \\
\hline & Education & -0.031 & 0.077 & -0.40 & 0.692 & -0.184 & 0.123 \\
\hline & Employment & -0.061 & 0.098 & -0.62 & 0.535 & -0.254 & 0.133 \\
\hline & Economic* & & & & & & \\
\hline & Other & -0.060 & 0.073 & -0.82 & 0.414 & -0.205 & 0.085 \\
\hline & Housing & -0.041 & 0.041 & -1.02 & 0.31 & -0.122 & 0.039 \\
\hline & Environment & 0.024 & 0.067 & 0.35 & 0.725 & -0.109 & 0.156 \\
\hline \multirow{2}{*}{$\begin{array}{c}\text { Number of } \\
\text { reasons }\end{array}$} & One* & & & & & & \\
\hline & Multiple & 0.078 & 0.033 & 2.39 & 0.019 & 0.013 & 0.143 \\
\hline Constant & & 4.168 & 0.070 & 59.30 & 0.000 & 4.029 & 4.308 \\
\hline
\end{tabular}

*Denotes reference category. Source: Statistics New Zealand, 2007.

frequently exhibited lower satisfaction, a result consistent with perpetual dissatisfaction often associated with 'chronic movers'.

Identifying with one of New Zealand's ethnic minorities - the fourth variable in Table 2-was associated with lower post-move satisfaction even after controlling for age and socio-economic status. It could be that minorities approach the move with higher expectations than they are able to realize but quite why this might be the case is unclear and therefore the negative coefficient on this ethnicity variable warrants closer attention than we have been able to give it here.

When it comes to cohabitation status, we find the greatest difference in post-move satisfaction outcomes is not between males and females in existing relationships, but 
rather between those who cohabit following a move and those who do not. This result highlights the importance of taking accompanying changes in domestic relations into account in any study of post-move satisfaction. Men and women who were single were less satisfied following their move, than movers who lived with a partner, with single men notably less well off than single women. While male movers appeared to benefit most from moving with a partner, the satisfaction benefits of cohabitation that women experienced may have more than outweighed any compromises that they may have made, in moving with their partner, as Mincer (1978) suggested. The magnitude of these differences in personal relationships is larger than any other single factor. One possible reason could be an associated change in housing tenure, from renting to owning, but the tenure variable necessary to test this hypothesis was not available from this survey.

The association between post-move satisfaction, education, occupation and income is also identifiable from the model estimates. Having a higher level of education did not have any appreciable effect on post-move satisfaction. However, managers and professionals did report a 0.13 points higher level of satisfaction with the outcomes of their move than individuals who were not in the labour force, a result which holds even in the presence of income. While the results for income do suggest that post-move satisfaction does rise with income, statistically the results are not significant and this could reflect the covariance structure of these three inter-correlated variables.

The impact of differences in the income of movers is conceptually and empirically distinct from the changes in income that accompany the move-recall the differences between income level and change in income in Table 2. Those whose income increased after moving to the new location reported positive (and statistically significant) levels of postmove satisfaction whether or not the change in income was related to the move ( 0.12 points higher) or not ( 0.10 points higher).

Movers appear to be more sensitive to moves associated with a fall in income than an increase in income, suggesting they are loss adverse. A decrease in income over the period of the move was negatively associated with the post-move satisfaction, but only if the loss of income was related to the move ( 0.20 points lower). At the same time, moving during a period of a negative change in a person's income does not significantly reduce the mover's perception of the success of the move. A move which mitigates a worsening situation may still be deemed a success if the move achieves the expectations of the mover.

Turning to urban hierarchy changes described in Table 2 we find that the moves taking place up and down the urban hierarchy (but within the commuting sheds bounded by local labour markets) showed little association with post-move satisfaction possibly because there were very few such instances (as indicated in Table 1). More relevant in Table 2 are intra local labour market moves where the influence of neighbourhood change plays a role. Movers were less satisfied with the outcome of moving when it involved moving into a less affluent neighbourhood than the one they left. Each decile increase in neighbourhood deprivation was associated with a decrease in satisfaction of 0.01 points on the post-move satisfaction scale.

The presence of forced moves in the sample was of particular interest. In a clear verification of the validity of the post-move satisfaction measure we found that those whose moves were forced were 0.13 points less satisfied than great majority of those who moved voluntarily (a result we also see repeated in the case of those moving between markets in 
Table 3). When it came to reasons for moving, we found there was little difference in postmove satisfaction between those whose primary motivation for moving was economic relative to those with other primary motives-a result consistent with an earlier analysis of this survey (Morrison and Clark 2011). We also learn that movers who cited multiple reasons for moving were more satisfied, by 0.07 points, than those who only provided one reason, suggesting that moves that improved life over several dimensions were associated with more likely satisfaction gains. Offering multiple reasons may also be associated with unobserved traits of these respondents themselves such as their greater ability to realize satisfaction over a variety of domains.

\section{Moving between local labour markets}

The same model applied to moves between local labour markets (internal migration) yielded a sparser set of significant estimates, in part due to their smaller number. As Table 3 shows, age, education and undertaking previous moves were not associated with better or worse satisfaction outcomes to any notable degree. This application also failed to support the hypothesis that older, more experienced movers are able to derive higher satisfaction from their move.

Several variables were positively associated with the 'way things turned out' for internal migrants; as with moves within the local labour markets, single men and women were less satisfied than couples with the outcomes of their move. Single men in particular were less likely to be satisfied with the way things turned out since the move. On average, newly single men were 0.81 points less satisfied than women who moved to another labour market with their partner.

The difference in post-move satisfaction outcomes of men and women in existing relationships can be contrasted with the discourse on tied migration. The magnitude of the difference in satisfaction between the men and women may reflect their relative economic success as well as their level of social capital. As we found above, while 'wives' may experience poorer economic outcomes when moving, their satisfaction with the overall outcomes of their move remains similar to their 'husbands', and there was a tendency towards more positive satisfaction when economic characteristics are controlled for. The greater post-move satisfaction of men may nevertheless have been more dependent on their economic outcomes than was the case for women.

As one might have expected, income at interview has a closer association with the postmove satisfaction of internal migrants than it did for movers, with higher earners more satisfied with the outcomes than those earning less than $\$ 20,000$ a year. As migrants, higher earners may have benefited from being able to draw on their higher income to prepare for their move and/or ameliorate any negative unforeseen outcomes (by being able to draw on employer assistance for example).

As noted in the previous section, the survey makes a valuable distinction between income and change in income over the moving interval. However, the change in income had a weaker association with the post-move satisfaction achieved by those crossing labour market boundaries than for those just moving within them. An increase in income, even if related to their internal migration, does not appear to be associated with an increase in the 
Table 3. Linear regression, moves between labour markets, New Zealand, 2007

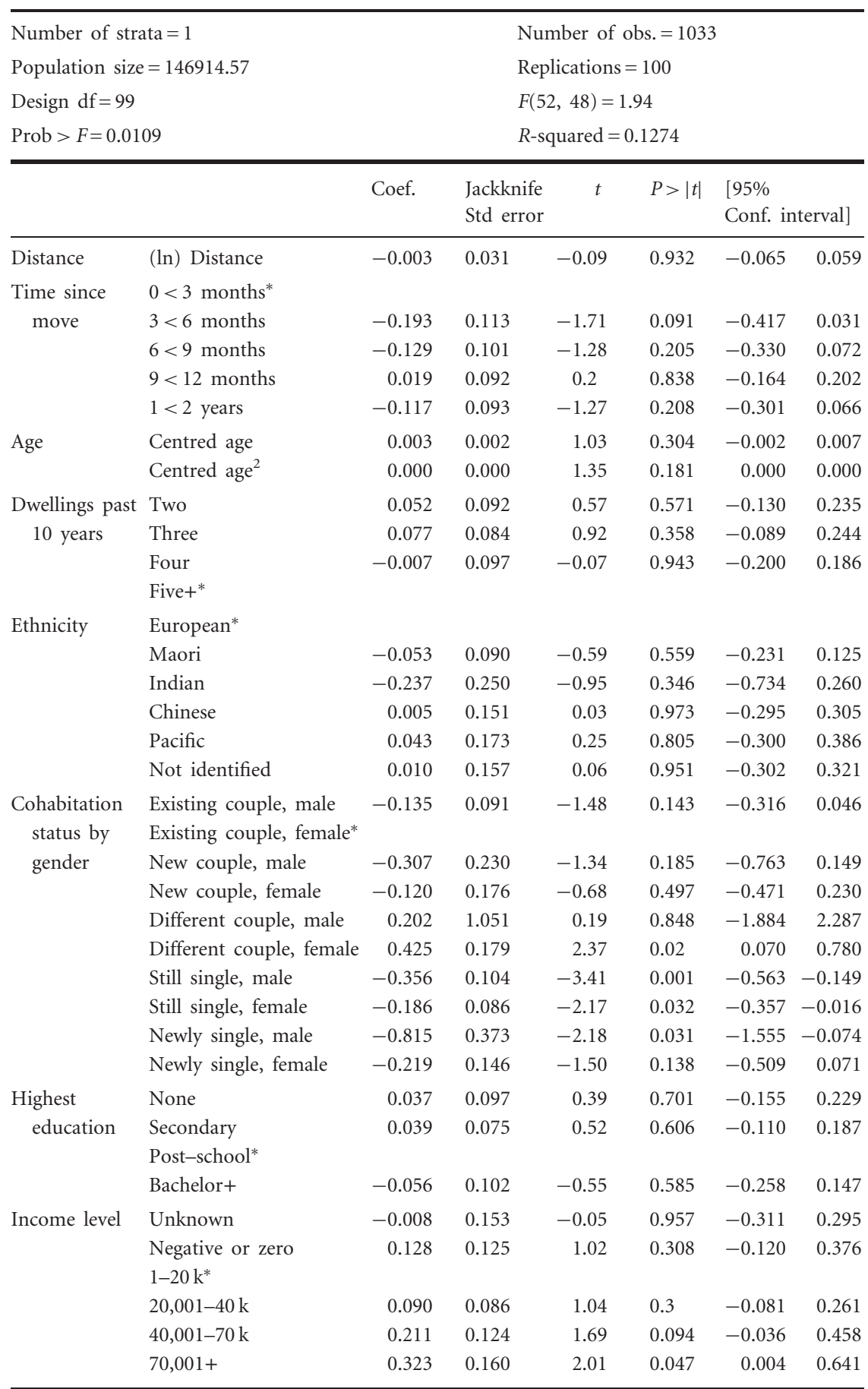


Table 3. Continued

\begin{tabular}{|c|c|c|c|c|c|c|c|}
\hline \multirow{4}{*}{$\begin{array}{l}\text { Change in } \\
\text { income } \\
\text { level }\end{array}$} & \multirow[b]{2}{*}{ No change* } & \multirow[t]{2}{*}{ Coef. } & \multirow[t]{2}{*}{$\begin{array}{l}\text { Jackknife } \\
\text { Std error }\end{array}$} & \multirow[t]{2}{*}{$t$} & \multirow[t]{2}{*}{$P>|t|$} & \multicolumn{2}{|c|}{$\begin{array}{l}{[95 \%} \\
\text { Conf. interval] }\end{array}$} \\
\hline & & & & & & & \\
\hline & $+($ result of move $)$ & -0.033 & 0.086 & -0.38 & 0.702 & -0.203 & 0.137 \\
\hline & + (unrelated to move) & 0.099 & 0.101 & 0.98 & 0.33 & -0.102 & 0.299 \\
\hline & - (result of move) & -0.237 & 0.115 & -2.06 & 0.042 & -0.466 & -0.008 \\
\hline & - (unrelated to move) & -0.189 & 0.128 & -1.48 & 0.142 & -0.442 & 0.065 \\
\hline \multirow[t]{6}{*}{ Occupation } & Not in labour force* & & & & & & \\
\hline & Unemployed & -0.128 & 0.136 & -0.94 & 0.352 & -0.398 & 0.143 \\
\hline & $\begin{array}{l}\text { Managers \& } \\
\text { professionals }\end{array}$ & 0.098 & 0.107 & 0.92 & 0.362 & -0.115 & 0.311 \\
\hline & Trades \& services & 0.145 & 0.108 & 1.34 & 0.183 & -0.070 & 0.360 \\
\hline & Primary \& secondary & 0.025 & 0.113 & 0.22 & 0.827 & -0.200 & 0.249 \\
\hline & Unknown & 0.049 & 0.136 & 0.36 & 0.718 & -0.220 & 0.318 \\
\hline \multirow{4}{*}{$\begin{array}{l}\text { Urban } \\
\text { hierarchy } \\
\text { change }\end{array}$} & $\mathrm{Up}$ & -0.032 & 0.086 & -0.38 & 0.708 & -0.202 & 0.138 \\
\hline & Lateral* & & & & & & \\
\hline & Down & 0.144 & 0.098 & 1.47 & 0.144 & -0.050 & 0.338 \\
\hline & Deprivation change & -0.001 & 0.009 & -0.10 & 0.923 & -0.019 & 0.017 \\
\hline \multirow[t]{2}{*}{ Forced } & $\mathrm{No}^{*}$ & & & & & & \\
\hline & yes & -0.212 & 0.092 & -2.31 & 0.023 & -0.394 & -0.030 \\
\hline \multirow{7}{*}{$\begin{array}{l}\text { Main reason } \\
\text { for moving }\end{array}$} & Social & 0.064 & 0.124 & 0.52 & 0.607 & -0.183 & 0.311 \\
\hline & Education & -0.146 & 0.188 & -0.78 & 0.439 & -0.519 & 0.227 \\
\hline & Employment & -0.119 & 0.122 & -0.98 & 0.33 & -0.361 & 0.122 \\
\hline & Economic* & & & & & & \\
\hline & Other & 0.025 & 0.173 & 0.14 & 0.885 & -0.319 & 0.369 \\
\hline & Housing & 0.068 & 0.165 & 0.41 & 0.682 & -0.260 & 0.395 \\
\hline & Environment & -0.023 & 0.139 & -0.16 & 0.872 & -0.299 & 0.254 \\
\hline \multirow{2}{*}{$\begin{array}{l}\text { Number of } \\
\text { reasons }\end{array}$} & One* & & & & & & \\
\hline & Multiple & 0.030 & 0.065 & 0.46 & 0.643 & -0.099 & 0.160 \\
\hline Constant & & 4.283 & 0.186 & 22.98 & 0.000 & 3.913 & 4.653 \\
\hline
\end{tabular}

*Denotes reference category. Source: Statistics New Zealand, 2007

migrant's outcome satisfaction. The lower satisfaction reported by migrants who experience a decrease in income when they moved is correspondingly negative and similar to that experienced by movers.

The findings of our model build on the existing body of post-move satisfaction literature by incorporating a number of variables that help to expose nuances in the satisfaction outcomes of movers and migrants. The association between income change and post-move satisfaction serves as a case in point, as does the difference in satisfaction outcomes experienced by single men and women. Where our variables align with previous studies, for example age and involuntary moves, we find generally similar results despite the differences in the measure of post-move satisfaction between studies. 


\section{Conclusion}

Residential mobility and migration research has been dominated by the search for geographic patterns and the causes of mobility. The theory itself is predicated on the reasonable assumption that migrants will not move voluntarily unless they believe they are going to be better off particularly in economic terms. However, studies of outcomes in terms of wages typically show a distribution of returns. A new and growing literature is now documenting the distribution of outcomes in subjective terms using measures which reflect movers and internal migrants' personal appraisal of the success of their move. They too are documenting a distribution of outcomes, both positive and negative.

The contribution of our paper is two-fold. Firstly, we have extended the measure of mobility outcomes to mover's level of satisfaction with the move itself. Our focus has not simply compared overall life satisfaction before and after the move. Rather we have drawn directly on a question which measures the mover's own assessment of the success of the move itself. The satisfaction response as a reflection of the degree to which expectations prior to the move have been realized and as such refocuses attention on the variables and processes which go into generating expectations and ensuring their realization. There is no inference here of any increase in fixed well-being scale.

Our second contribution has been to explicitly distinguish between 'mobility' and 'migration'; the former involved any change of address within the same local labour market, and the second, crossing from one local labour market to another. There is nothing novel in this distinction of course; rather its relevance lies in the ways such moves are assessed, by respondents. In contrast to moves involving only a change in dwelling, those accompanied by a change in local labour market involved fewer people, greater uncertainty, and a less positive distribution of returns.

In addition to our refinement of the study of post-move satisfaction itself, the results themselves have a number of implications. The first, apparent from Figure 2 alone, is that those who change the place they live in experience a variety of outcomes, not all of which are positive. The modelling assumption that people will only move when expected returns are positive can hardly be framed otherwise. However, the reality is that things do not always turn out for the best and that we should expect marked differences and try and understand why. A second implication of our study is the way it has highlighted the need to take a more comprehensive view of changes associated with the move. Changes of residence do not occur in isolation. On the contrary, they are often intimately associated with other changes in the life course, in particular changes in partnership and residence. These accompanying changes colour and influence the success of moves often overriding any purely environmental changes. But possibly the most important implication of our study is the way it has underscored the importance of the subjective, of allowing movers and migrants themselves to express their own view of the outcomes of their move. While as social scientists we may want to take measures of objective changes such as wages, in practice most changes of address are multifaceted and driven by a whole variety of factors which would be very difficult to capture in objective terms. One of the values of the subjective is that the respondents themselves summarize the net effect of all these simultaneous events into a single assessment of the value of the change to them. 
As if to underscore this last point, one of the additional values of the survey we have analysed was the attention it paid to changes coincident with the move. We already know that moves are often precipitated or triggered by other, often domestic, events and perhaps not surprisingly we find that changing address jointly with a partner is associated with a more satisfying outcome especially for male respondents moving into another local labour market.

At the same time, our study of post-move satisfaction has highlighted several challenges. While we have attached conceptual importance to the role of expectation and of realization in interpreting satisfaction ratings of the move, the variables which play a role in each separately are not identified nor are they well understood in the literature. The innovation we see applied to the development of dependent variable in the post-move satisfaction literature now needs to be extended more deeply into the right hand side of the equation, in order to capture shifts of those accompanying changes in economic and personal relationships that accompany changes of address both within and between local labour markets. This of course underscores the relative value of the longitudinal or panel study in future research.

\section{Funding}

This project was funded in part by the Department of Labour Graduate Research Scholarship Scheme and a Victoria University Faculty of Science Strategic Research grant.

\section{Acknowledgements}

Access to the data used in this study was provided by Statistics New Zealand under conditions designed to give effect to the security and confidentiality provisions of the Statistics Act 1975. The results presented in this study are the work of the authors, not Statistics New Zealand.

Conflict of interest statement. None declared.

\section{Notes}

1. Because the DMM survey uses a complex sampling method, regression analysis utilises jack-knife replication weights provided by Statistics New Zealand.

2. In the source document the lead author has applied both logit and OLS and demonstrates their comparability (Sloan 2013)

3. We make this inference in full recognition of the cross sectional nature of the survey and the possibility that movers who were less satisfied with their move may have relocated and be lost to the sample.

\section{References}

Akay, A. and Bargain, O. (2012) 'Relative Concerns of Rural-to-Urban Migrants in China', Journal of Economic Behaviour \& Organisation, 81/2: 421-41. 
Allen, J. (1979) 'Information and Subsequent Migration: Further Analysis and Additional Evidence', Southern Economic Journal, 45/4: 1274-84.

Barcus, H. (2004) 'Urban-rural Migration in the USA: An Analysis of Residential Satisfaction', Regional Studies, 38/6: 643-57.

Bartram, D. (2013) 'Happiness and "Economic Migration"; a Comparison of Eastern European Migrants and Stayers', Migration Studies, 1/2: 156-75.

—_. (2011) 'Economic Migration and Happiness: Comparing Immigrants and Natives' happiness gains from income', Social Indicators Research, 103/1: 57-76.

Chhetri, P., et al. (2009) 'Why bother to "downshift"? The characteristics and satisfaction of downshifters in the Brisbane-South East Queensland region, Australia', Journal of Population Research, 26/1: 51-72.

Clark, A. E. et al. (2008) 'Lags and Leads in Life Satisfaction: a Test of the Baseline Hypothesis', The Economic Journal, 118/529: F222-43.

Cooke, T. J. (2008) 'Migration in a Family Way', Population, Space and Place, 14/4: 255-65.

DaVanzo, J. (1981) 'Repeat Migration, Information Costs, and Location-Specific Capital', Population \& Environment, 4/1: 45-73.

De Jong, G. F., Chamratrithirong, A. and Tran, Q. (2002) 'For Better, for Worse: Life Satisfaction Consequences of Migration', International Migration Review, 36/3: 838-63.

European Commission. (1994) Eurobarometer No. 41: Public Opinion in the European Union. (Brussels: European Commission).

Ferrer-i-Carbonell, A. and Frijters, P. (2004) 'How Important is Methodology for the estimates of the determinants of Happiness?', The Economic Journal, 114/497: 641-59.

Grant, E. K. and Vanderkamp, J. (1986) 'Repeat Migration and Disappointment', Canadian Journal of Regional Science, 9/3, 299-322.

Haybron, D. M. (2011) 'Taking the Satisfaction (and the Life) out of Life Satisfaction', Philosophical Explorations, 14: 249-262.

Kau, J. B. and Sirmans, C. F. (1976) 'New, Repeat, and Return Migration: A Study of Migrant Types', Southern Economic Journal, 43/2: 1144-48.

Kleinhans, R. (2003) 'Displaced but Still Moving Upwards in the Housing Career? Implications of Forced Residential Relocation in the Netherlands', Housing Studies, 18/4: 473-99.

Knight, J. and Gunatilaka, R. (2010) 'Great Expectations? The Subjective Well-being of Rural-Urban Migrants in China’, World Development, 38/1: 113-24.

Lu, M. (1999) 'Determinants of Residential Satisfaction: Ordered Logit vs. Regression Models', Growth and Change, 30/2: 264-87.

—. (2002) “'Are Pastures Greener?" Residential Consequences of Migration', International Journal of Population Geography, 8/3: 201-16.

Lundholm, E. and Malmberg, G. (2006) 'Gains and Losses, Outcomes of Interregional Migration in the Five Nordic Countries', Geografiska Annaler: Series B, Human Geography, 88/1: 35-48.

Massey, Douglas S. et al. (1993) 'Theories of International Migration: A Review and Appraisal', Population and Development Review, 19/3: 431-66.

McKelvey, R. and Zavoina, W. (1975). 'A Statistical Model for the Analysis of Ordinal Level Dependent Variables', Journal of Mathematical Sociology, 4: 103-20. 
Mincer, J. (1978) 'Family Migration Decisions', The Journal of Political Economy, 86/5: 749-73.

Morrison, P. S. and Clark, W. A. V. (2011) 'Internal Migration and Employment: Macro Flows and Micro Motives', Environment and Planning A, 43/8: 1948-64.

Nowok, B. et al. (2011) 'Does Migration Make You Happy? A Longitudinal Study of Internal Migration and Subjective Well-being'. Discussion Paper series.

_- (2013) 'Does Migration Make You Happy? A Longitudinal Study of Internal Migration and Subjective Well-being', Environment and Planning A, 45: 986-1002.

Papps, K. L. and Newell, J. O. (2002) 'Identifying Functional Labour Market Areas in New Zealand: A Reconnaissance Study Using Travel-to-work Data', Institute for Study of Labour, Bonn. Discussion Paper No. 443.

Polgreen, L. and Simpson, N. (2011) 'Happiness and International Migration', Journal of Happiness Studies, 12/5: 819-40.

Rossi, P. H. (1955) Why Families Move: A Study in the Social Psychology of Urban Residential Mobility. Glencoe, Illinois: Free Press.

Ryan, C. (2012) 'Responses to financial stress at life transition points'. FaHCSIA, Canberra. Occasional Paper Series No. 41.

Simpson, N.B. (2011) 'Happiness and Migration', in Zimmerman, K. and Constant, A. (eds), International Handbook on the Economics of Migration, pp. 393-408. Cheltenham, UK and Northampton, USA: Edward Elgar Publishing Ltd.

Sjaastad, L. A. (1962) 'The Costs and Returns of Human Migration', The Journal of Political Economy, 70/5.2: 80-93.

Sloan, M. K. (2013) 'The Post-move Satisfaction of Individuals Moving Within New Zealand', PhD Thesis, Victoria University of Wellington, Wellington, New Zealand.

Statistics New Zealand. (2011) 'Household Labour Force Survey Resource-Statistics New Zealand:' <http://www.stats.govt.nz/surveys_and_methods/our-surveys/hlfs-resource. aspx>, accessed 3 March 2015.

White, P. et al. (2008) Atlas of Socioeconomic Deprivation in New Zealand. NZDep2006. Wellington, New Zealand: Ministry of Health.

Yezer, A. M. J. and Thurston, L. (1976) 'Migration Patterns and Income Change: Implications for the Human Capital Approach to Migration', Southern Economic Journal, 42/4: 693-702.

Zax, J. S. (1994) 'When is a Move a Migration', Regional Science and Urban Economics, 24/ 3: 341-60.

Ziegler, J. A. and Britton C. R. (1981) 'A Comparative Analysis of Socioeconomic Variations in Measuring the Quality of Life', Social Science Quarterly (University of Texas Press), 62/2: 303-12. 